\title{
A Phosphorus Index transport factor based on variable source area hydrology for New York State
}

\author{
R.D. Marjerison, H. Dahlke, Z.M. Easton, S. Seifert, and M.T. Walter
}

\begin{abstract}
The Phosphorus (P) Index concept is used in many states to help develop nutrient management plans for livestock agriculture to protect water quality. Although many $\mathrm{P}$ indices conceptually incorporate variable source area (VSA) runoff processes, they generally assume proximity to a water course is an adequate proxy of runoff risk. Here we propose aVSA-based transport factor that uses the topographic index concept to indicate runoff risk. We compared both transport factors based on the current New York State P Index and our VSA-based P Index to field measures of runoff probability across an abandoned agricultural site in upstate New York. We also compared transport factors and P indices using the current and VSAbased approaches on a farm in the Catskill Mountains of New York to evaluate differences at whole-field and farm scales. Field runoff-risk measurements were better correlated with VSA-based transport factor $\left(r^{2}=0.63, \alpha=0.05\right)$ than with the current dissolved-P transport factor $\left(r^{2}=0.40, \alpha=0.05\right)$. Although these point-scale differences in transport factor values translated into field-scale differences in transport factor, the net differences at the farm scale and in P Index were not very large. On a field-by-field basis, 12 out of 21 fields had different transport factor categories with the VSA method. However, the total land area classified as high risk changed very little between the two methods. There was more land classified as moderate risk using the VSA-based approach than using the current methods, due to some low risk areas being classified as higher risk and some high-risk areas being classified as lower risk. The VSA approach allows managers and producers to more easily manage farm units (e.g., fields) at finer resolutions both spatially and temporally, which will increase the options for managing nutrients on fields. These types of more rigorous links between management tools and physical hydrology provide valuable, more scientifically defensible information for improving our ability to control nonpoint source pollution.
\end{abstract}

Key words: nutrient management—Phosphorus Index—variable source areas

This paper proposes a variable source area (VSA) based transport factor for incorporation into an existing Phosphorus (P) Index to give farmers and nutrient management planners improved information about the relative risks of runoff from different parts of a farm. Phosphorus in agricultural runoff often contributes to eutrophication of streams and other fresh water systems (Carpenter et al. 1998). The P Index is a widely used tool for managing phosphorus $(\mathrm{P})$ from nonpoint sources (NPS), which helps identify fields or parts of the landscape that are particularly susceptible to $\mathrm{P}$ loss, including P-enriched runoff (Sharpley et al. 2003). The information contained in the P Index is used in farm nutrient management plans to strategize manure spreading, fertilization, and other management decisions to reduce risks of NPS P transport to streams.

The New York State (NYS) P runoff index was developed by a multiagency work group based on existing knowledge of NPS pollution and runoff (Czymmek et al. 2003). The NYS P Index consists of a "transport" factor and a "source" factor that are multiplied together to quantify the P Index for a certain field or management unit. In the NYS P Index, there are two risk scores based on two different transport factors: one for dissolved $\mathrm{P}$ and one for particulate $\mathrm{P}$. The transport factors address the likelihood that water or sediment from a specific field will reach a stream based largely on the distance between the field and a stream, the frequency of flooding as given by a soil survey, and, for dissolved $\mathrm{P}$, the drainage class of soils. The dissolved-P transport factor is designed to address saturation excess runoff. The particulate $\mathrm{P}$ transport factor incorporates the erodability of the soil and presence of concentrated flow paths in addition to the distance to a stream and the frequency of flooding. The source factor is an indication of the amount of $\mathrm{P}$ available that potentially could be entrained into storm runoff and includes soil test $\mathrm{P}$, applied fertilizer, applied manure, and the timing and method of fertilizer or manure applications. The weights for most of the factors were assigned based on the best scientific or expert knowledge available to the developers. The NYS P Index identifies the relative risk from a field rather than quantifying how much P (i.e., mass of P) from that field will reach a stream. The few studies that have tried to quantitatively validate the P Index have had encouraging results. For example, Veith et al. (2005) found good agreement between P Index categories and modeled P losses from a test watershed in Pennsylvania. DeLaune et al. (2004) also found a significant correlation between estimates of $\mathrm{P}$ loss using the Arkansas P Index.

While the above-mentioned studies suggest the P Index is successful to some degree at predicting relative risk, there are factors in potential P loss that are not included in the current NYS P Index. For example, Easton et al. (2008b) found that the most effective manure management practices are those that disassociate manure spreading from areas prone to generate storm runoff, which are not always characterized as high risk using the simple distance to the stream metric (e.g., Agnew et al. 2006).

Saturated areas occur where the net amount of water coming into an area exceeds the water storage capacity of that area. Some parts of the landscape - specifically, places with a high contributing area,

Rebecca D. Marjerison and Helen Dahlke are graduate students and Zachary $M$. Easton is an assistant professor at Virginia Polytechnic Institute and State University, Blacksburg, Virginia. Shannon Seifert is a graduate student and $M$. Todd Walter is an associate professor in the Department of Biological and Environmental Engineering, Cornell University, Ithaca, New York. 
shallow soils, shallow slopes, and low saturated hydraulic conductivity-will be more susceptible to producing runoff than others. Indeed, for much of the Northeast, the most rapid hydrologic flow paths have long been associated with variable saturated areas more commonly referred to as variable source areas (VSAs); e.g., Dunne and Black 1970; Dunne and Leopold 1978; Srinivasan et al. 2002; Walter et al. 2003; Needleman et al. 2004; Easton et al. 2007). These runoff-generating areas expand and contract from storm to storm, as well as seasonally.Variable source area hydrology is probably also important in other humid areas with steep topography and shallow, high infiltration capacity soils (e.g., Walter et al. 2000).

The NYS P Index incorporates a logical scheme for accounting for VSAs in its transport factor by rating areas close to streams as having a high risk of generating runoff. The distance between the field edge and the nearest receiving water body is assumed to indicate the risk of runoff from that field. Previous efforts to include VSA hydrology into water quality protection strategies have used a similar logic, varying the width of stream buffers based on the runoff contributing area for given storm return periods (Gburek et al. 2002; Sharpley et al. 2008). Of the 47 states with a $\mathrm{P}$ Index, 31 have included some kind of contributing area based on distance from concentrated flowpaths in the transport calculation (Sharpley et al. 2003). However, studies on the effects of fixed-width riparian buffers on dissolved-P concentrations in streams have had inconsistent results at best, and in some cases buffers have been shown to contribute to dissolvedP loads (Hoffmann et al. 2009). Agnew et al. (2006) showed that runoff-generating VSAs do not consistently correlate well to simple stream proximity. Thus, we speculate that the documented good performance of $\mathrm{P}$ indices (e.g., DeLaune et al. 2004; Veith et al. 2005) may be more strongly attributed to the source factor than the transport factor. We suggest that a P Index transport factor that uses more physically realistic VSA concepts will be a better predictor of a field's risk of producing runoff.

The objectives of this research were to compare the current NYS P Index dissolved$\mathrm{P}$ transport factor with a newly developed transport factor that is based more robustly on VSA hydrology. The current and proposed $\mathrm{P}$ Index transport factors were compared to field data from a study site in central NYS and to an example farm in the Catskill Mountains, NYS.

An Improved, Variable Source Area-Based Transport Factor. A VSA-based transport factor for dissolved $\mathrm{P}$ was developed using a soil topographic index (STI). We used the variable source loading function (VSLF) watershed model (Schneiderman et al. 2007) to determine which fields were most at risk of generating runoff. The topographic index concept is largely attributed to Beven and Kirkby (1979), although similar indices were developed by O'Laughlin (1981) and Moore et al. (1993) and have been subsequently modified by numerous hydrological modelers. Soil topographic index-based models have been used and incorporated into several hydrologic models (e.g.,VSLF, Schneiderman et al. 2007; Soil and Water Assessment Tool (SWAT), Easton et al. 2008a), and showed good agreement with observed stream flow, soil moisture, and water table depths across a range of conditions. These STI indices are used to qualitatively rank areas in the watershed in terms of their overall probability of saturating and generating runoff. The STI for a unit of landscape is the ratio of water flowing in (as determined by contributing area) to water flowing out (as determined by Darcy's Law). The STI used here is as follows:

$S T I=\ln \left(\frac{a}{K_{s} D s}\right)$,

where $a$ is upslope contributing area per unit contour length $(\mathrm{m}), s$ is the tangent of the topographic slope $(-), K_{s}$ is mean saturated hydraulic conductivity of the soil above a restricting layer $\left(\mathrm{m} \mathrm{d}^{-1}\right)$, and $D$ is soil depth $(\mathrm{m})$; note, this form is from Walter et al. (2002) and is slightly different from many popular forms.

The STI is used to divide the watershed into 10 equal-area STI classes, with class 1 representing the lowest $10 \%$ of STI values (least likely to generate runoff) and 10 representing the highest $10 \%$ of values (most likely to generate runoff). Unfortunately, the relationship between STI and probability of generating storm runoff is not linear (e.g., Agnew et al. 2006) so we propose running a distributed hydrological model on representative regional watersheds to develop the STI-runoff probability relationship. This relationship can then be extrapolated to similar watersheds (Agnew et al. 2006), which might not have sufficient data to initialize the model. The runoff probability is the frequency or fraction of days that a point in the landscape is saturated on days when there is enough rain to generate runoff somewhere in the watershed-i.e., effective precipitation $(P-P E T>0)$. Here we use the VSLF model (Schneiderman et al. 2007) to determine the probability of runoff on days with effective precipitation for each STI class. This model has been shown to reliably predict soil moisture at $10 \times 10 \mathrm{~m}(33 \times 33 \mathrm{ft})$ scales (Schneiderman et al. 2007; Easton et al. 2008b). We propose using the probability of runoff determined (between 0 and 1) as the transport factor in the P Index for dissolved P.

\section{Materials and Methods}

To test our proposed (VSA-based) P Index transport factor, we first compared its relative risk values (0 to 1 ) and those of the current NYS P Index dissolved-P transport factor to field measures of shallow groundwater depth. The dissolved-P transport factor was chosen because VSA hydrology deals with saturation excess, which is the runoff mechanism addressed by the dissolved-P transport factor (Czymmek et al. 2003). Additionally, dissolved $\mathrm{P}$ is more bioavailable and therefore of more immediate threat to streams. An effective transport factor should ideally correlate to field measures such that high-risk values (close to 1) correspond to a groundwater table near the soil surface.

The second phase of testing was to compare the VSA-based transport factor to the current dissolved-P transport factor as determined by an officially approved nutrient management planner. We made this comparison on one farm to determine to what degree the proposed transport factor leads to different interpretations of high- and lowrisk fields.

For both tests, the STI was calculated using United States Geological Survey (USGS) 10 m (33 ft) digital elevation models (DEMs) (for slope and contributing area) and soil data from the USDA Natural Resources Conservation Service (NRCS) SSURGO database (for soil depth and saturated hydraulic conductivity). The DEM was corrected to reflect artificial drainage systems (field tiles and ditches) installed in the study farm (Easton et al. 2008b). The TauDEM tools (Tarboton 1997) were used to calculate the slope and contributing area. The Soil Data Viewer tool, available from NRCS, was used 
to extract soil data from the SSURGO database. The locations, soil transmissivities, and STI class distribution for each study area are shown in figure 1.

Test 1: Comparisons to Field Measurements. The two different transport factor methods were tested against measured water levels from a 1 ha $(2.5 \mathrm{ac})$ section of an inactive agricultural field in central NYS. The field is in the Salmon Creek watershed, near Ithaca. The site is located in the glaciated Allegheny Plateau physiographic region. The annual average temperature is $8^{\circ} \mathrm{C}\left(46^{\circ} \mathrm{F}\right)$, average annual precipitation is $93 \mathrm{~cm}$ (37 in), with $173 \mathrm{~cm}$ (68 in) of snowfall annually. Salmon Creek watershed covers $230 \mathrm{~km}^{2}$ (56,834 ac), about $70 \%$ of which is agricultural land, $28 \%$ is mixed forest, and the remaining $2 \%$ is residential, commercial, and urban. Soils at the site are silt loams and gravelly silt loams, 200 cm (79 in) deep (SSURGO, USDA NRCS). Elevations range from 320 to $378 \mathrm{~m}(1,050$ to $1,240 \mathrm{ft})$. The site where we measured saturation is on recently ( $3 \mathrm{y})$ abandoned cropland in the southern part of the watershed. An ephemeral stream runs through the site. Twenty-four wells were installed to the fragipan (e.g., coarse-loamy, mixed, active, mesic, to frigid Typic Fragiudepts, Lytic, or Typic Dystrudepts common to glacial tills) at depths of approximately $50 \mathrm{~cm}$ (20 in) in two transects that cross the ephemeral streambed (figure 1a). An additional well was installed in the path of the stream at the downstream end of the site. Each well was fitted with an Odyssey pressure sensor and data recorder (Dataflow Systems PTY LTD, Christchurch, New Zealand). The area covered by the well network is about $10,000 \mathrm{~m}^{2}(2.5 \mathrm{ac})$. Water levels in the wells were measured at 15-minute intervals for approximately two years. We calculated the percent of days above saturation, also referred to as probability of saturation, for each well by dividing the number of days the well was above saturation (defined as a water level less than $10 \mathrm{~cm}$ [4 in] below ground surface [Lyon et al. 2006]) by the number of days the well recorded data.

The VSA-based transport factor was determined using the STI class of each well location and the associated probability of runoff as determined by the VSLF simulation of the watershed used in Test 2. The current $\mathrm{P}$ Index dissolved-P transport factor for each well location was determined by applying the guidelines defined by Czymmek et al.

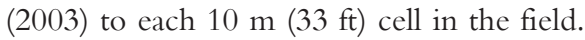

\section{Figure 1}

Location and distribution of soil topographic index (STI) classes ( $a$ and b) and soil transmissivity ( $c$ and d) of study sites. ( $a$ and $c$ ) field site for Test 1 and ( $b$ and d) field site for Test 2 . Cells in soil topographic index class 1 are least likely to saturate; those in class 10 are most likely to saturate. The triangles in (a) and (c) indicate piezometer locations, and the dashed lines in (c) indicate stream channels.

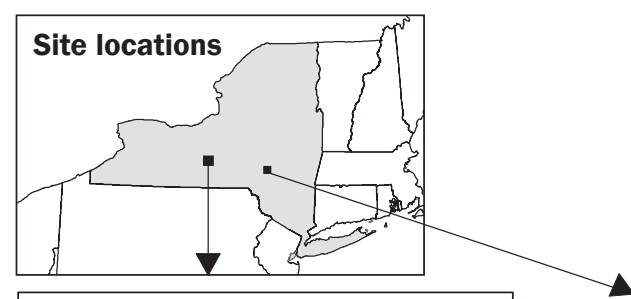

(a)

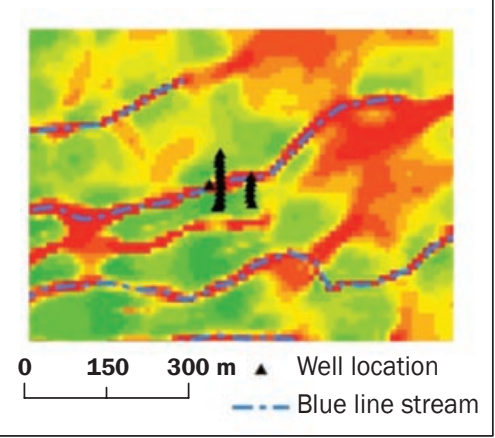

(c)

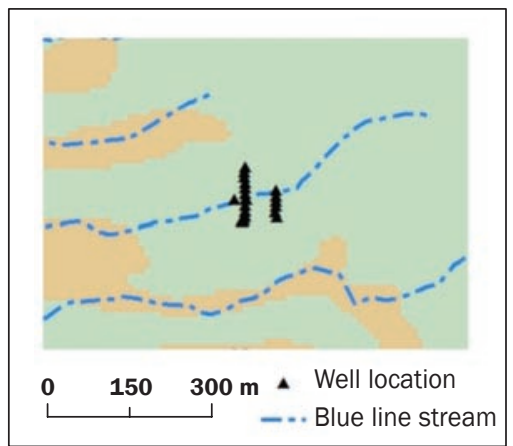

(b)

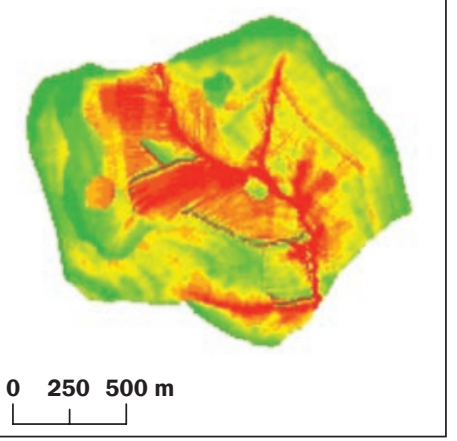

(d)

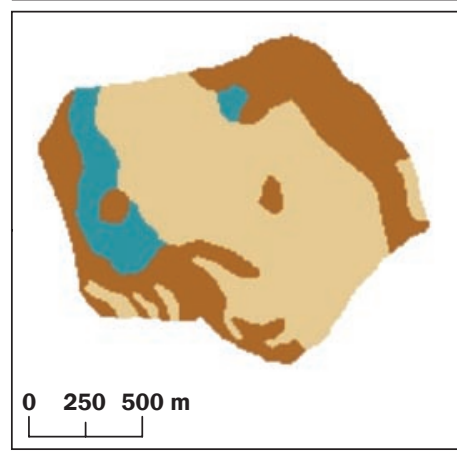

Legend

STI wetness class

$\square$
$\square$
$\square$
$\square$
$\square$
$\square$
$\square$
$\square$
6
$\square$
$\square$
$\square$
10

Contributing factors for the current P Index are shown in table 1 . The transport risks predicted by the VSA-based method and by the current P Index dissolved-P transport factor were compared to the average probability that a given well location was saturated. We recognize that the current $\mathrm{P}$ Index transport factor is not meant to be applied at subfield scales, but because the specifics of the guidelines incorporate subfield information, we have applied it to specific points in the landscape for purposes of comparison.

Test 2: Comparison of the Variable Source Area-Based to Current Transport Factor. The VSA-based dissolved-P transport factor was calculated for a farm in Catskill Mountains, 
NYS. The subwatershed that covers most of the farm has an area of $1.6 \mathrm{~km}^{2}$ (395 ac) and is part of the Cannonsville watershed. The land use in this test watershed is $52 \%$ deciduous forest, 33\% pasture and hay, $7 \%$ row crops, 3\% stream buffer, 3\% brushland, and $2 \%$ impervious surfaces of roads, barnyard, and pond (Rao et al. 2009). Elevations range from 600 to $739 \mathrm{~m}(1,970$ to $2,425 \mathrm{ft})$. Soils are channery loams and channery silt loams, 28 to $201 \mathrm{~cm}$ (11 to 79 in) deep. The site has annual average temperatures of $8^{\circ} \mathrm{C}$ $\left(46^{\circ} \mathrm{F}\right)$, average annual precipitation of 112 $\mathrm{cm}$ (44 in) and average snowfall of $160 \mathrm{~cm}$ (63 in) annually. Figure 2 shows the layout of the farm including the drainage network. The STI was calculated for each $10 \mathrm{~m} \mathrm{(33}$ $\mathrm{ft}$ ) grid cell, and the VSLF-modeled probability of runoff was assigned to each cell based on its STI class. The transport factor for a field was determined by spatially averaging the transport factors of all the cells in the field. The VSA-based transport factor for each field was compared to the existing dissolved-P transport factor as determined by a certified nutrient management planner.

\section{Results and Discussion}

Test 1. Probabilities of saturation based on water table measurements were regressed against the VSA-based transport factor and against the current $\mathrm{P}$ Index dissolved$\mathrm{P}$ transport factor to determine which approach was a better predictor of runoff generation (figures $3 \mathrm{a}$ and $3 \mathrm{~b}$, respectively). According to VSA hydrology, areas where the soil saturates more often are more prone to generating storm runoff. Both approaches were positively correlated with water table depth and, thus, captured the general patterns of anticipated runoff generation. However, the proposed VSA-based transport factor was a better predictor of which wells were likely to saturate; $r^{2}=0.63(p=0.0007)$ for VSA-based transport factor and $r^{2}=0.40(p$ $=0.0476$ ) for current transport factor (both correlations are significant, $\alpha=0.05)$. Both transport factors correctly identified the wettest wells, but the current dissolved-P transport factor was somewhat more conservative in that it failed to correctly predict any of the 10 well sites that never saturated, i.e., generated storm runoff.

Test 2. While our first test shows a somewhat better relationship between the VSA-based transport factor and point-runoff potential than the current dissolved-P transport factor, it is not obvious that there will
Table 1

Calculation of the New York State Phosphorus (P) Index dissolved-P transport factor (adapted from Czymmek et al. 2003). Scores are determined for soil drainage, flooding frequency, and flow distance characteristics, and a composit factor is calculated as the sum of these three scores: dissolved $\mathrm{P}$ transport factor ${ }^{\star}=$ soil drainage score + flooding frequency score + flow distance score.

\begin{tabular}{lll}
\hline $\begin{array}{lll}\text { Contributing } \\
\text { factor }\end{array}$ & Values & Score \\
\cline { 2 - 3 } Soil drainage & Description & 0.1 \\
& Well to excessively well drained & 0.3 \\
& Moderately well drained & 0.7 \\
& Somewhat poorly drained & 1.0 \\
& Poorly or very poorly drained & 0 \\
Flooding frequency & Rare/never $(>100$ years $)$ & 0.2 \\
& Occasional (10 to 100 years $)$ & 1.0 \\
Flow distance to & Frequent $(<10$ years $)$ & 0 \\
blue line stream $(\mathrm{ft}) \dagger$ & Intermittent stream $(>200 \mathrm{ft})$ & $1-($ distance -25$) / 175$ \\
& Intermittent stream $(25 \mathrm{to} 200 \mathrm{ft})$ & 1 \\
& Intermittent stream $(<25 \mathrm{ft})$ & 0 \\
& Perennial stream $(>300 \mathrm{ft})$ & $1-($ distance -50$) / 250$ \\
& Perennial stream $(50 \mathrm{to} 300 \mathrm{ft})$ & 1 \\
\hline
\end{tabular}

*If the dissolved-P transport factor exceeds 1 , the value is set to 1 .

† Defined as distance to blue line stream ( $\mathrm{ft}$ ) as depicted on a topographic map and confirmed based on field evaluation. Intermittent streams are

generally depicted with a dashed blue line on topographic maps, and perennial streams are shown with a solid blue line.

\section{Figure 2}

Field layout and drainage network for the farm used in Test 2.

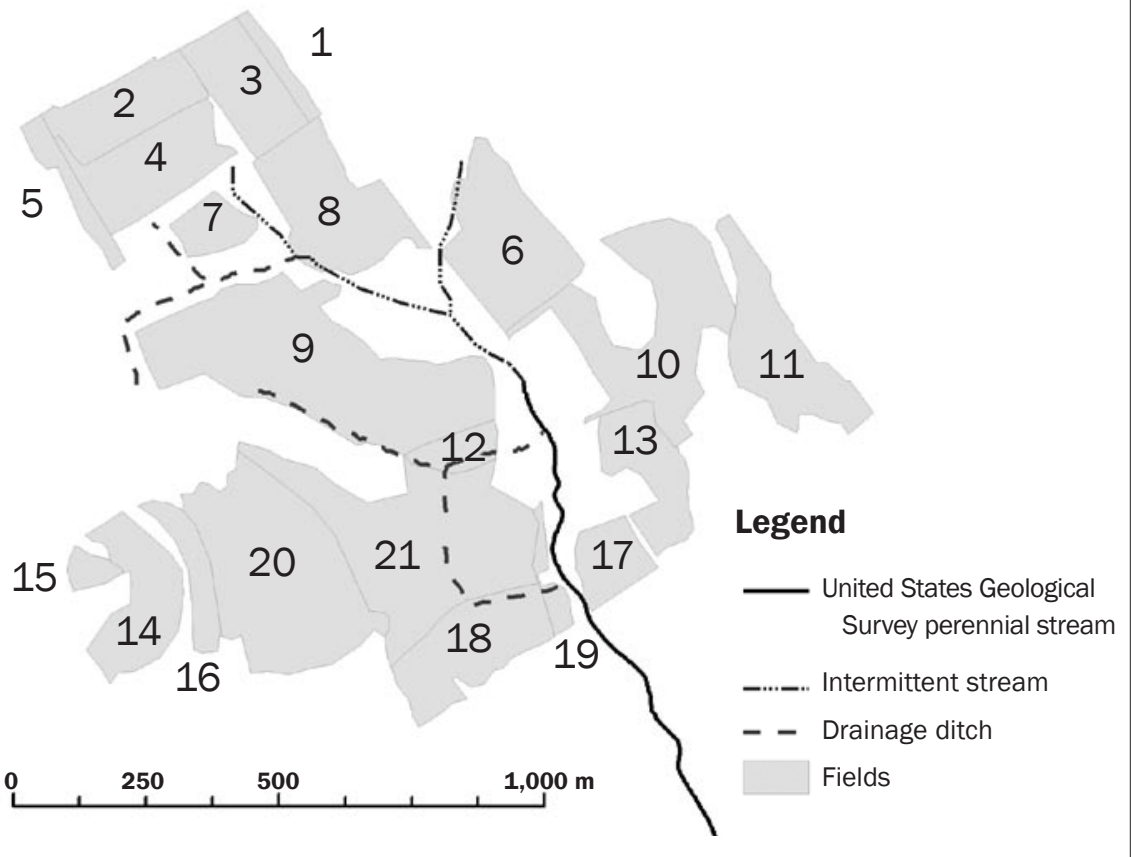




\section{Figure 3}

(a) Relationship between measured probability of saturation and variable source area (VSA)based transport factor (modeled probability of saturation based on soil topographic index class). (b) Relationship between measured probability of saturation and Phosphorus (P) Index dissolved-P transport factor. Straight lines are linear regressions, $r^{2}=0.63$ and $r^{2}=0.40$ for (a) and (b), respectively (both significant, $\alpha=0.05$ ).

(a)

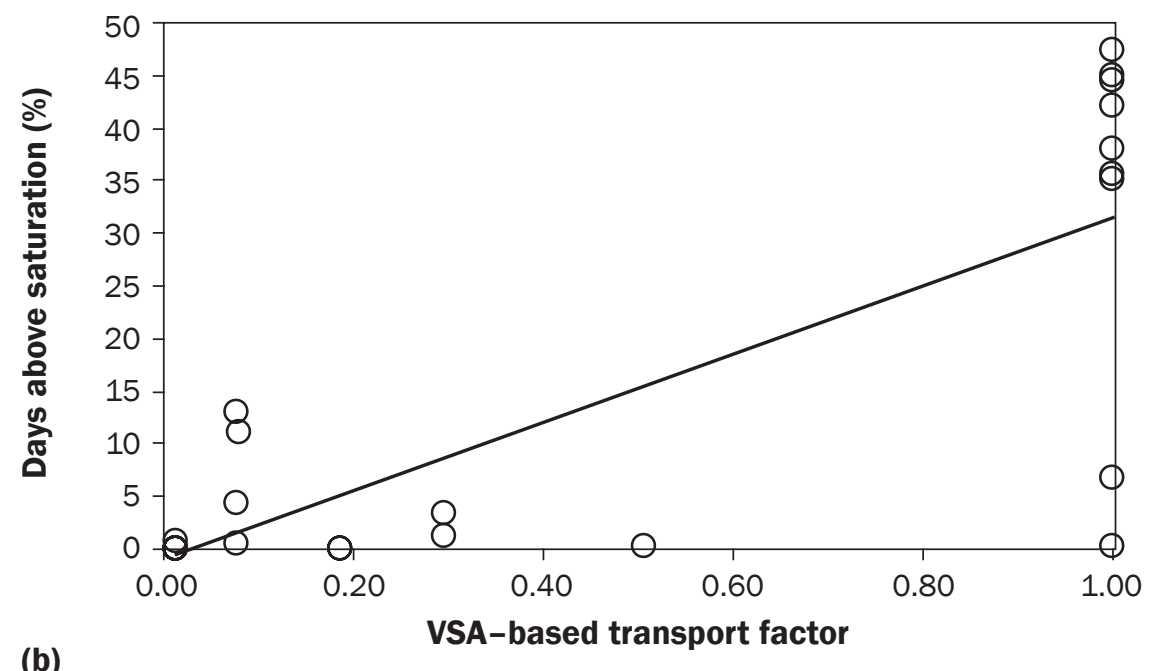

(b)

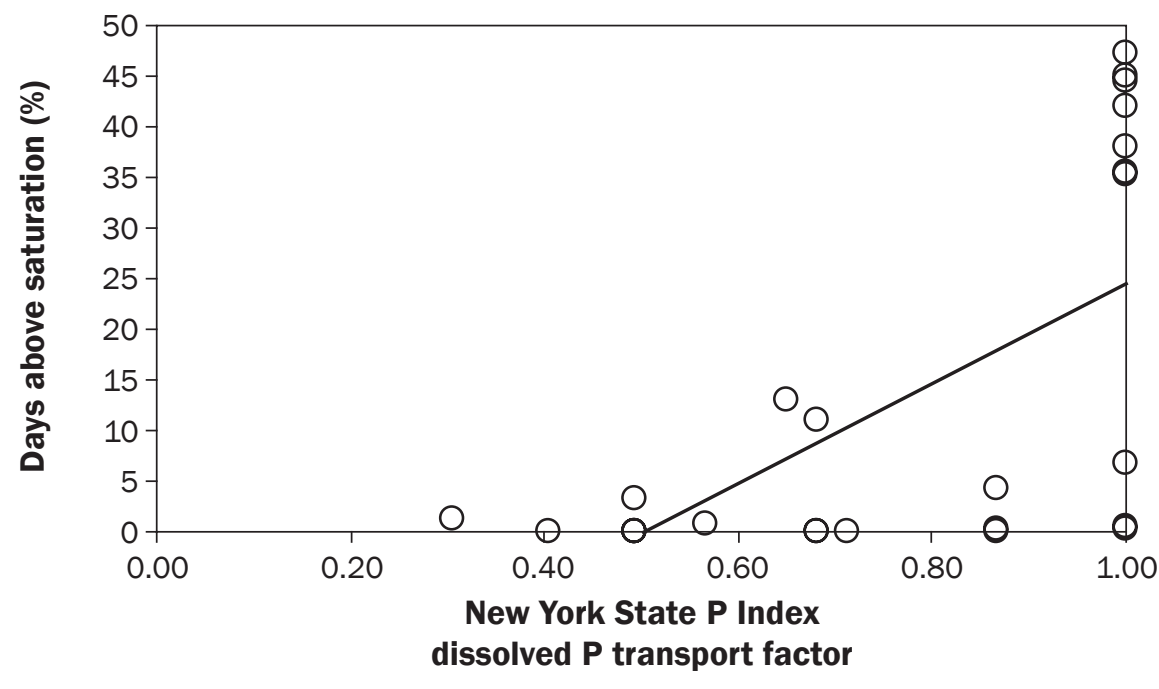

be any substantial differences in transport factors at the field scale. For ease of comparison, the transport factor results were divided into three equal categories: low (0 to 0.33$)$, medium (0.34 to 0.66$)$, and high (0.67 to 1.0) risks (figure 4). These designations are arbitrary and are not connected to the categories of the P Index, which influence how a field is managed. The VSA-based transport factor identified eight fields at higher risk than the current dissolved-P transport factor, four fields at lower risk, and no change for nine fields. Table 2 summarizes the amount of land area in each of three categories for each transport factor. The VSA-based transport factor categorized more land area as "medium" than "low" risk as compared to the current method, but the high-risk category covers nearly the same percent of the land area with both methods. Note, however, that the fields in each category are often different (figure 4). Because the amount of land categorized as high risk was the same with both methods, there would be little added restriction to agricultural management by adopting our VSA-based transport factor.

The two methods compared here for determining a transport factor are based on very different parameters, but the results do have some similarities. Nearly half of the fields in the study area were in the same transport risk category regardless of which method was used. Both transport factors classified about $78 \%$ of the land area in the low or medium categories for risk of transporting dissolved P (table 2).

Certain fields (e.g., fields 2 and 4) were identified as low risk by the current method because the travel distance to the stream exceeds the distance considered at risk $(90$ $\mathrm{m}$ [300 ft] for perennial streams, $60 \mathrm{~m}$ [200 $\mathrm{ft}]$ for intermittent streams). The VSA-based transport factor does not account for distance to stream and therefore identified those fields as high risk because they have low slope and large upslope contributing area. Conversely, several fields that are close to streams (and therefore higher risk in the current method) have relatively low contributing areas so their risk level was lower based on the VSAbased method (e.g., fields 13 and 17; figure 4). Generally speaking, if there is a low risk of generating VSA (saturation excess) runoff, the distance to the stream is less important.

The VSA based transport factors varied by land use as well, but not in any consistent way. For hay fields, six fields had no change, two increased, and one decreased, with the VSAbased dissolved-P transport factor relative to the current factor. For pasture, one field had no change, four increased, and one decreased. For cropland, two fields had no change, two increased, and two decreased.

Phosphorus Index. The current and proposed transport factors were also combined with the current source factors, determined by nutrient management planners, to create $P$ Index values for each field (figure 5). The threshold for implementing P-control best management practices (BMPs) in NYS is a $\mathrm{P}$ Index of 50 while a P Index less than 50 is considered a low-risk area (Czymmek et al. 2003). The fields in the study area generally had low P Index values regardless of which method was used to determine the transport factor in part because this watershed was a long-term research site for agricultural water quality (e.g., Frankenberger et al. 1999; Walter et al. 2001a, 2001b) and a test site for BMPs (e.g., Bishop et al. 2005; Easton et al. 2008b). The average $\mathrm{P}$ Index for all fields is 16 for the new VSA-based method and 12 for the current method. The current and VSA-based $\mathrm{P}$ indices classify, respectively, 98\% and 95\% 


\section{Figure 4}

Comparison of Phosphorus (P) Index transport factors for study area. (a) Current transport factor is based on soil characteristics and distance to stream. (b) Variable source area (VSA)-based transport factor uses a soil topographic index that incorporates upslope contributing area, soil depth, topographic slope, and saturated hydraulic conductivity.

(a)

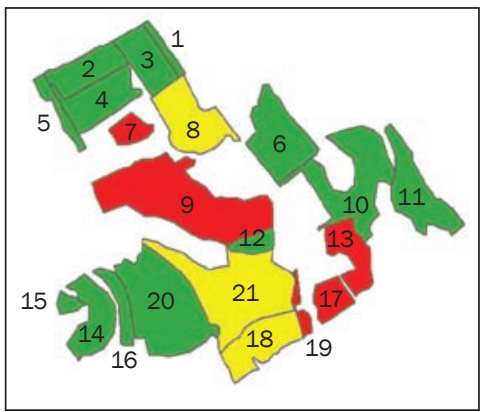

Current $\mathbf{P}$ Index dissolved $\mathbf{P}$ transport factor (b)

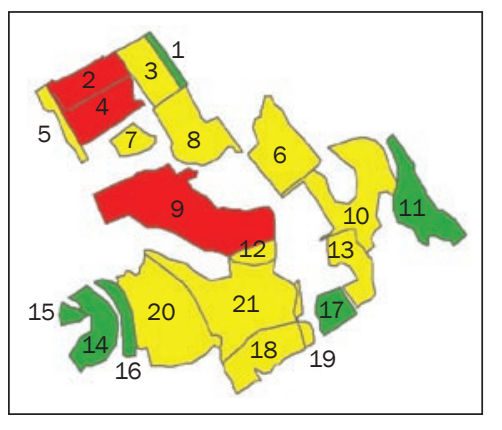

VSA-based transport factor

\section{Legend}

Transport factor

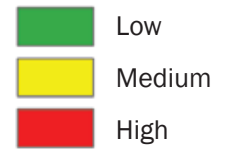

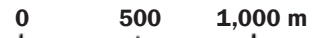

Table 2

Comparison of dissolved phosphorus transport factors.

\begin{tabular}{llllll}
\hline $\begin{array}{l}\text { Transport } \\
\text { factor } \\
\text { category }\end{array}$ & $\begin{array}{l}\text { Transport } \\
\text { factor } \\
\text { value }\end{array}$ & $\begin{array}{l}\text { VSA method } \\
\begin{array}{l}\text { Land area } \\
\text { (ha) }\end{array}\end{array}$ & Total (\%) & $\begin{array}{l}\text { Current method } \\
\text { land area (ha) }\end{array}$ & Total (\%) \\
\hline Low & 0 to 0.33 & 12 & 15 & 44 & 56 \\
Medium & 0.34 to 0.66 & 50 & 62 & 19 & 22 \\
High & 0.67 to 1.00 & 19 & 23 & 18 & 22 \\
\hline
\end{tabular}

Note: VSA = variable source area.

of the managed land area in the low-risk category for overall vulnerability to P loss.

The current NYS P Index includes the presence of "concentrated flow paths" in the particulate $\mathrm{P}$ portion of the Index but not in the dissolved-P portion. Concentrated flow paths are likely to carry not only particulate $\mathrm{P}$, but also dissolved P, toward the stream, as these $\mathrm{P}$ fractions are often transported together. While these flow paths are not explicitly factored into the VSA transport factor, they are naturally included in the method because contributing area has been shown to be correlated to concentrated flow paths (Zhu and Lin 2009). A DEM with sufficient resolution will show where concentrated flow paths are. As with the farm site in this study, features such as artificial drainage networks can be incorporated into the DEM for even more accurate reflection of the hydrology.

Soil Topographic Index Values. Table 3 shows the average values for the STI components for each field in the study watershed, along with the modeled probability of runoff on days with effective precipitation based on the average STI class for the field. In this case, the best predictor of probability of runoff was upslope contributing area $\left(r^{2}=0.54\right.$, $\alpha=0.05)$, followed by the soil depth $\left(r^{2}=\right.$ $0.36, \alpha=0.05)$ and slope $\left(r^{2}=0.33, \alpha=\right.$ $0.05)$. Saturated hydraulic conductivity did not vary much over the study area; thus, it did not influence differences in STI class or probability of runoff significantly. Note that none of these characteristics is incorporated into the current NYS P Index dissolved-P transport factor.
Variations in Time and Space. Inherent in VSA hydrology is the fact that saturated areas, or runoff source areas, vary in both time and space. A major advantage of the VSA-based method for determining $\mathrm{P}$ transport risk is the ability to treat fields in a spatially and temporally explicit manner (i.e., allow planners and producers to work at subfield or subseasonal scales). Figure 6 shows an example of VSA transport factors at the subfield level. In this case there are fields (e.g., field 21) that are predominantly low risk with some higher risk areas that influence the field average. If the planner or producer considers only the field scale, the entire field must be managed at a mediumrisk level. However, if runoff risk is assigned to locations within a field, manure or fertilizer could be spread on lower risk areas of the field, while avoiding the higher risk areas. Obviously these results have implications on precision agriculture in that improved nutrient management and water quality can be implemented simultaneously.

Figure 7 shows how saturated areas can change over time. A relatively wet month, April, is contrasted with the driest month, August. At the field scale, four fields are in the low category in August but in the medium category in April. At the subfield scale, there are areas in most fields that are lower risk in August than in April. Incorporating spatial and temporal variability in nutrient management planning will help provide producers with flexibility in optimizing the location and timing of manure or fertilizer applications while still protecting streams from excess P.

The similarity in the two final P Index values despite obvious differences in the transport factors suggests that the P Index is controlled more by the source factor than the transport factor. The dissolved-P transport factor has a maximum value of 1 , so it is often masked by a source factor that can take on very high values. This could be a problem in areas where $\mathrm{P}$ should not be added such as flow paths directly connected to streams. One suggestion is that a threshold transport factor be considered, above which no additional P may be added. For the NYS P Index, a similar threshold exists for the source factor. Exactly what the transport factor threshold should be is beyond the scope of this study.

Implementation. The creation of an STI requires data that are free and readily available for download from government 


\section{Figure 5}

The Phosphorus (P) Index (a) as currently determined and (b) using the variable source area (VSA)-based transport factor. (c) The source factors are shown for reference.

(a)

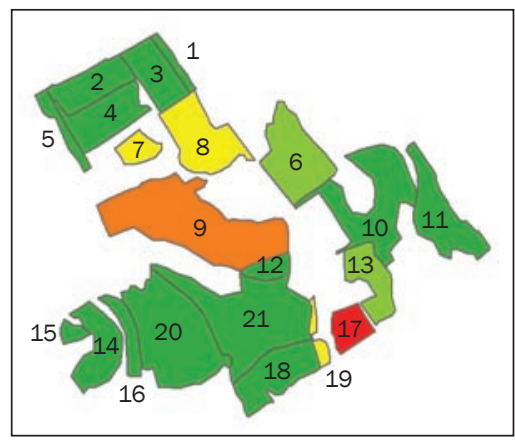

Current P Index

(c)

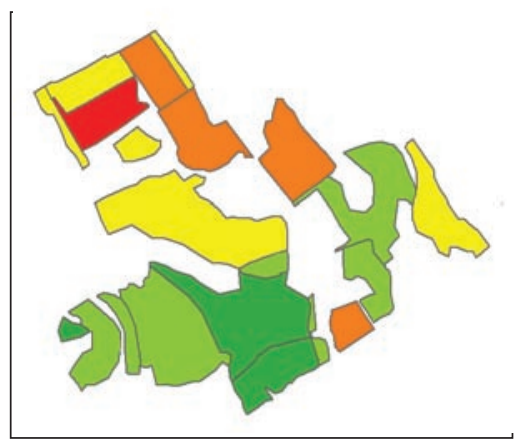

$P$ Index source factor (b)

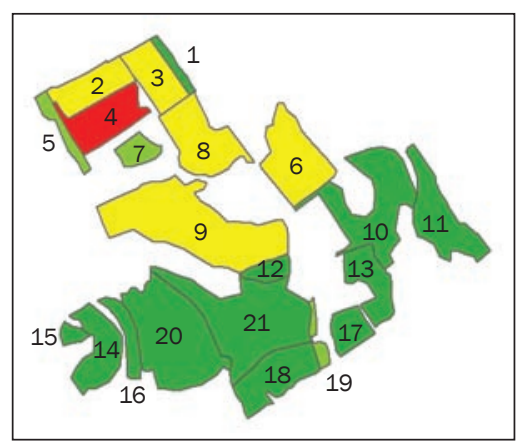

VSA-based P Index

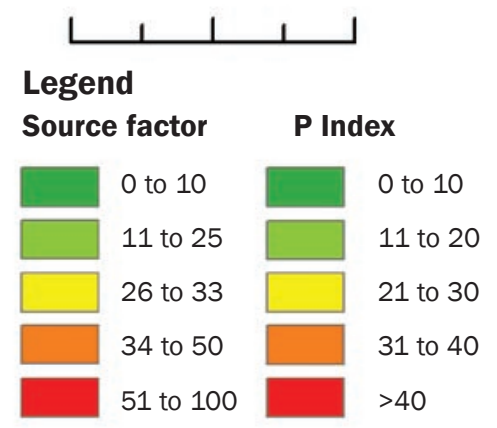

Table 3

Soil topographic index parameters (averaged by field) and the variable source area (VSA)based transport factor.

\begin{tabular}{llllll}
$\begin{array}{l}\text { Field } \\
\text { number }\end{array}$ & $\boldsymbol{K}_{\mathbf{s}}\left(\mathbf{m ~ d ~}^{-\mathbf{1}}\right)$ & $\begin{array}{l}\text { Soil depth, } \\
\boldsymbol{D}(\mathbf{m})\end{array}$ & Slope, $\boldsymbol{s}$ & $\begin{array}{l}\text { Contributing } \\
\mathbf{a r e a}, \boldsymbol{a}\left(\mathbf{m}^{\mathbf{2}}\right)\end{array}$ & $\begin{array}{l}\text { VSA-based } \\
\text { transport factor }\end{array}$ \\
\hline 1 & 1.07 & 0.95 & 93 & 0.12 & 0.26 \\
2 & 0.78 & 1.13 & 451 & 0.07 & 0.84 \\
3 & 0.78 & 1.00 & 136 & 0.07 & 0.55 \\
4 & 0.78 & 1.31 & 577 & 0.08 & 0.81 \\
5 & 0.78 & 1.18 & 307 & 0.15 & 0.58 \\
6 & 0.78 & 1.43 & 448 & 0.08 & 0.55 \\
7 & 0.78 & 1.47 & 211 & 0.07 & 0.51 \\
8 & 0.80 & 1.29 & 801 & 0.08 & 0.56 \\
9 & 0.78 & 1.40 & 630 & 0.08 & 0.76 \\
10 & 0.78 & 1.12 & 235 & 0.16 & 0.46 \\
11 & 0.78 & 0.78 & 40 & 0.19 & 0.08 \\
12 & 0.78 & 1.23 & 427 & 0.12 & 0.50 \\
13 & 0.78 & 1.21 & 222 & 0.11 & 0.50 \\
14 & 0.78 & 0.69 & 66 & 0.15 & 0.28 \\
15 & 0.78 & 0.81 & 38 & 0.15 & 0.12 \\
16 & 0.78 & 0.73 & 91 & 0.20 & 0.28 \\
17 & 0.78 & 1.20 & 52 & 0.07 & 0.18 \\
18 & 0.78 & 0.91 & 603 & 0.11 & 0.55 \\
19 & 0.78 & 1.22 & 977 & 0.14 & 0.64 \\
20 & 0.78 & 0.66 & 187 & 0.16 & 0.45 \\
21 & 0.78 & 1.02 & 211 & 0.15 & 0.37
\end{tabular}

websites: a DEM (e.g., seamless.usgs.gov) and soils data (e.g., SSURGO, datagateway.nrcs. usda.gov). The National Elevation Dataset includes DEMs of at least $1 / 3$ arc-second

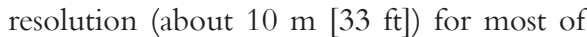
the conterminous United States. Hawaii is covered at 1 arc-second and Alaska at 2 arc-second resolution. Soils data are available for most of the conterminous United States and Hawaii. Geographic information system (GIS) software is also required. Time and effort could be saved by creating STI maps for a large area such as a county or soil and water conservation district. Most conservation district offices have GIS capabilities, although somewhat varied in level of expertise (A. Barber, Cortland County Soil and Water Conservation District). Thus, the required data and expertise are widely available for making STI maps. Relating STI maps to probabilities of saturation requires either intensive soil moisture monitoring over regionally representative areas and over acceptably long time periods or, as done in this study, the application of a VSA model. The data necessary for the VSLF model used here include precipitation, soils, and temperature data and land use, many of which are required to determine current $\mathrm{P}$ indices; i.e., little additional data are required to adopt the VSA-based dissolved-P transport factor. Admittedly, the expertise for running these models is probably not as ubiquitous as GIS expertise, but we have found that relatively few watersheds need to be modeled to capture regional VSA patterns and behavior (Agnew et al. 2006; Shaw and Walter 2009). Therefore, the model could be initialized and run once by a trained individual for a region (county, soil conservation district, physiographic region, etc.) and the resulting VSA transport factors applied to individual farms or sites by planners. Dissolved-P transport factor maps could be made available through soil and water conservation districts or, perhaps, incorporated into the available tools like the USDA NRCS online Soils Reader.

\section{Summary and Conclusions}

We demonstrated the application of VSAbased hydrology to nutrient management planning, using modeled probability of runoff as a new transport factor in the $\mathrm{P}$ Index. This VSA-based transport factor provided better estimation of actual saturation in monitored locations than the current $\mathrm{P}$ Index dissolved-P transport factor. In a field- 
scale comparison, looking only at the average transport factor for each field, the VSA-based transport factor placed more land area in the medium-risk category than the current dissolved-P transport factor, but there was no increase in how much land would be categorized as high risk. However, the locations of the high-risk fields were different. The VSAbased transport factor potentially allows planners and farmers more flexibility to plan applications of manure or fertilizer based on the characteristics of the land at larger spatial and temporal scales than they currently use.

\section{Acknowledgements}

We would like to acknowledge USDA Cooperative State Research, Education, and Extension Service (grant 0051130-9777) and the Cornell Agricultural Experiment Station (Hatch grant) for funding this research. We wish to thank Chris Berry and Todd Anderson from the Cornell Soil and Water Lab for their valuable assistance in maintaining our field monitoring activities, Tammo Steenhuis for his advice and support for this project, and Peter Wright and the USDA NRCS office in Syracuse, NYS, for their persistent support in these activities.

\section{References}

Agnew, L.J., S. Lyon, P. Gerard-Marchant, V.B. Collins, A.J Lembo,T.S. Steenhuis, and M.T. Walter. 2006. Identifying hydrologically sensitive areas: Bridging the gap between science and application. Journal of Environmental Management 78 (1):63-76.

Beven, K.J., and M.J. Kirkby. 1979. A physically-based, variable contributing area model of basin hydrology. Hydrological Science Bulletin 24:43-69.

Bishop, P.L., W.D. Hively, J.R. Stedinger, M.R. Rafferty, J.L. Lojpersberger, and J.A. Bloomfield. 2005. Multivariate analysis of paired watershed data to evaluate agricultural best management practice effects on stream water phosphorus. Journal of Environmental Quality 34(3):1087-1101.

Carpenter, S.R., N.F. Caraco, D.L. Correll, R.W. Howarth, A.N. Sharpley, andV.H. Smith. 1998. Nonpoint pollution of surface waters with phosphorus and nitrogen. Ecological Applications 8(3):559-568.

Czymmek, K.J., Q.M. Ketterings, L.D. Geohring, and G.L. Albrecht. 2003. The New York Phosphorus Runoff Index User's Manual and Documentation. CSS Extension Publication E03-13. Ithaca, NY: Crop and Soil Sciences Departent, Cornell University.

Delaune, P.B., P.A. Moore, D.K. Carman, A.N. Sharpley, B.E. Haggard, and T.C. Daniel. 2004. Evaluation of the phosphorus source component in the Phosphorus Index for pastures. Journal of Environmental Quality 33 (6):2192-2200

\section{Figure 6}

(a) Variable source area (VSA)-based transport factor at subfield scale, compared to (b) current Phosphorus (P) Index dissolved-P transport factor and (c) VSA-based transport factor at the field-scale.

(a)

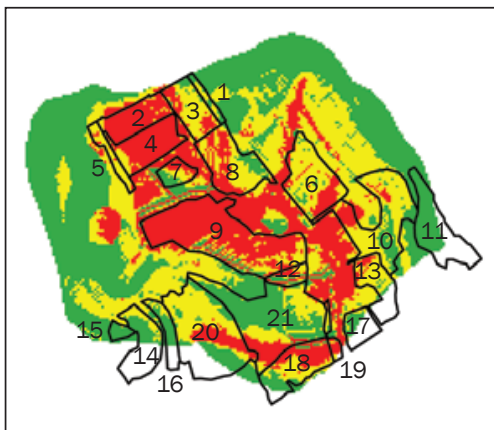

VSA-based transport factor at subfield scale

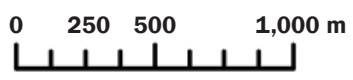

Legend Transport factor

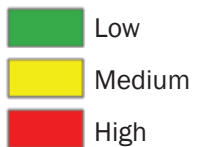

(b)

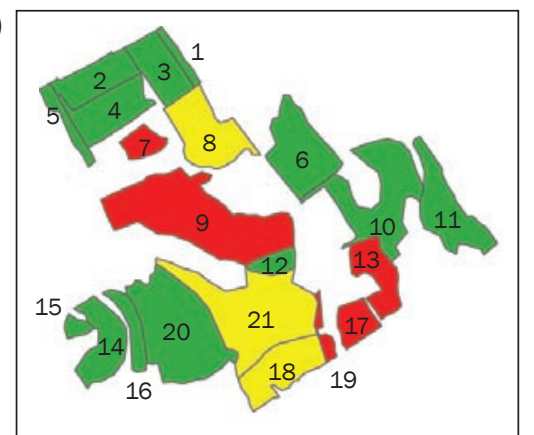

\section{Current P Index dissolved-P transport factor}

(c)

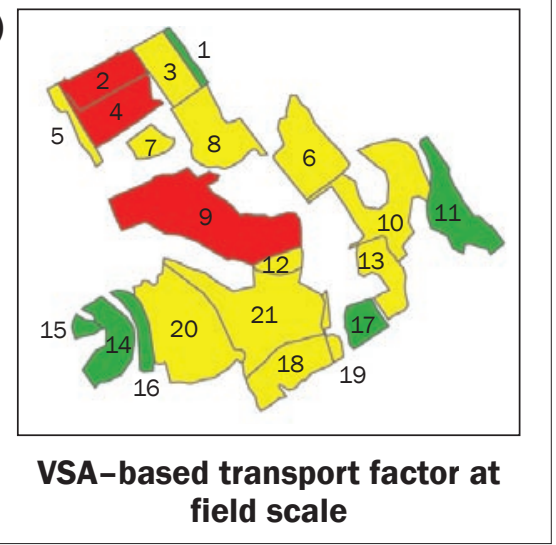

Gburek, W.J., C.C. Drungil, M.S. Srinivasan, B.A. Needelman, and D.E. Woodward. 2002. Variable-sourcearea controls on phosphorus transport: Bridging the gap between research and design. Journal of Soil and Water Conservation 57(6):534-543.

Hoffmann, C.C., C. Kjaergaard, J. Uusi-Kamppa, H.C.B. Hansen, and B. Kronvang. 2009. Phosphorus retention in riparian buffers: Review of their efficiency. Journal of Environmental Quality 38(5):1942-1955

Lyon, S.W., J. Seibert, A.J. Lembo, M.T. Walter, and T.S. Steenhuis. 2006. Geostatistical investigation into the temporal evolution of spatial structure in a shallow water table. Hydrology and Earth System Science 10(1):113-125

Moore, I.D., T.W. Norton, and J.E. Williams. 1993. Modeling environmental heterogeneity in forested landscapes. Journal of Hydrology 150 (2-4):717-747.

Oloughlin, E.M. 1981. Saturation regions in catchments and their relations to soil and topographic properties. Journal of Hydrology 53(3-4):229-246.

Needelman, B.A., W.J. Gburek, G.W. Petersen, A.N. Sharpley, and P.J. Kleinman. 2004. Surface runoff along two agricultural hillslopes with contrasting soils. Soil Science Society of America Journal 68:914-923. 


\section{Figure 7}

April and August variable source area (VSA)-based transport factors as examples of temporal differences in transport factors at ( $a$ and $b$ ) subfield and ( $c$ and $d$ ) field scales.

(a)

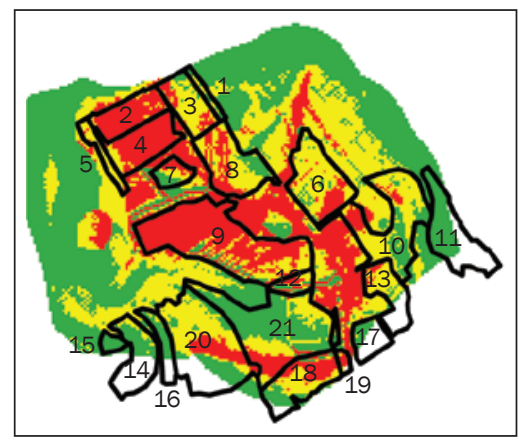

\section{VSA-based transport factor in April at subfield scale}

(c)

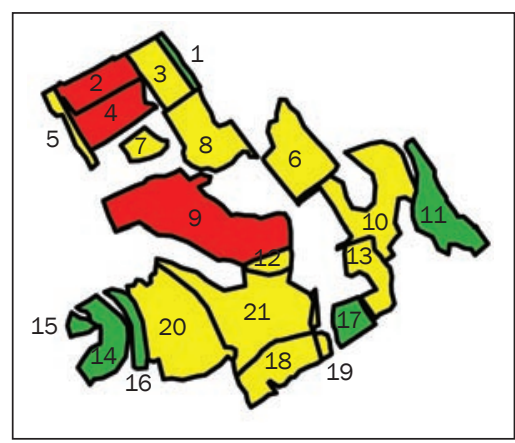

VSA-based transport factor in April at field scale (b)

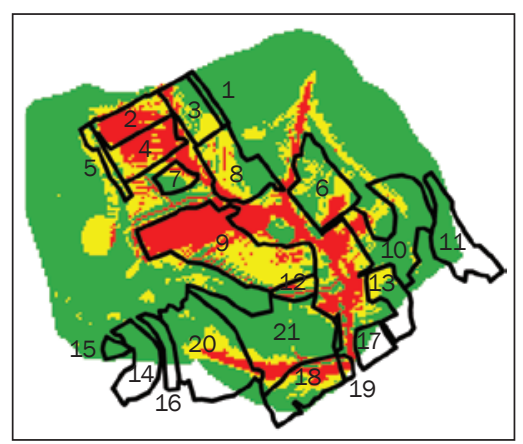

VSA-based transport factor in August at subfield scale

(d)

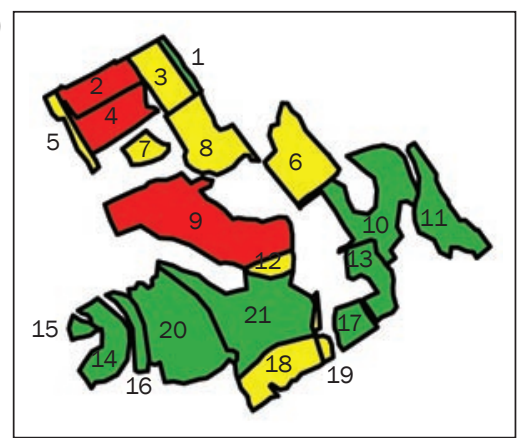

VSA-based transport factor in August at field scale

Legend

Transport factor
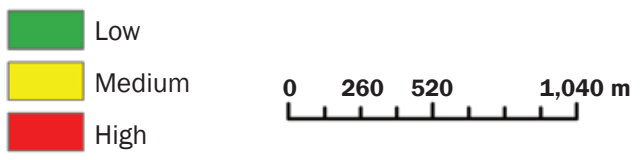

digital elevation models. Water Resources Research 33(2):309-319.

Veith, T.L., A.N. Sharpley, J.L. Weld, and W.J. Gburek. 2005

Comparison of measured and simulated phosphorus losses with indexed site vulnerability. Transactions of the American Society of Agricultural Engineers 48(2):557-565

Walter, M.T., E.S. Brooks, M.F. Walter, T.S. Steenhuis, C.A. Scott, and J.Boll. 2001a. Evaluation of soluble phosphorus transport from manure-applied fields under various spreading strategies. Journal of Soil and Water Conservation 56(4):329-336.

Walter, M.T., V.K. Mehta, A.M. Marrone, J. Boll, P. GerardMarchant, T.S. Steenhuis, and M.F. Walter. 2003. Simple estimation of prevalence of Hortonian flow in New York City watersheds. Journal of Hydrologic Engineering 8(4):214-218

Walter, M.T., J.-Y. Parlange, M.F. Walter, X. Xin, and C.A. Scott. 2001b. Modeling pollutant release from a surface source during rainfall-runoff. Journal of Environmental Quality 30(1):151-159.

Walter, M.T., T.S. Steenhuis, V.K. Mehta, D.Thongs, M. Zion, and E. Schneiderman. 2002. Refined conceptualization of TOPMODEL for shallow subsurface flows. Hydrological Processes 16(10):2041-2046.

Walter, M.T., M.F Walter, E.S. Brooks, T.S. Steenhuis, J. Boll, and K. Weiler. 2000. Hydrologically sensitive areas: Variable source area hydrology implications for water quality risk assessment. Journal of Soil and Water Conservation 55(3):277-284.

Zhu, Q., and H.S. Lin. 2009. Simulation and validation of concentrated subsurface lateral flow paths in an agricultural landscape. Hydrology and Earth System Sciences 13(8):1503-1518.
Rao, N.S., Z.M. Easton, E.M. Schneiderman, M.S. Zion, D.R. Lee, and T.S. Steenhuis. 2009. Modeling watershedscale effectiveness of agricultural best management practices to reduce phosphorus loading. Journal of Environmental Management 90(3):1385-1395.

Schneiderman, E.M.,T.S. Steenhuis, D.J.Thongs, Z.M.Easton, M.S. Zion, A.L. Neal, G.F. Mendoza, and M.T. Walter. 2007. Incorporating variable source area hydrology into a curve-number-based watershed model. Hydrological Processes 21(25):3420-3430.

Sharpley, A.N., P.J.A. Kleinman, A.L. Heathwaite, W.J. Gburek, J.L.Weld, and G.J. Folmar. 2008. Integrating contributing areas and indexing phosphorus loss from agricultural watersheds. Journal of Environmental Quality 37(4):1488-1496.
Sharpley, A.N., J.L. Weld, D.B. Beegle, P.J.A. Kleinman, W.J. Gburek, P.A. Moore, and G. Mullins. 2003. Development of phosphorus indices for nutrient management planning strategies in the United States. Journal of Soil and Water Conservation 58(3):137-152. Shaw, S.B., and M.T. Walter. 2009. Formulating storm runoff risk using bivariate frequency analyses of rainfall and antecedent watershed wetness. Water Resources Research 45:W03404.

Srinivasan, M.S., W.J. Gburek, and J.M. Hamlett. 2002. Dynamics of stormflow generation: A field study in east-central Pennsylvania, USA. Hydrological Processes 16(3):649-665.

Tarboton, D.G. 1997. A new method for the determination of flow directions and contributing areas in grid 